Supplementary Material for

\title{
High Peel Strength and Flexible Aligned Carbon Nanotubes/Etched Al Foil Composites with Boosted Supercapacitor and Thermal Dissipation Performances
}

Juan Du, ${ }^{1,2}$ Le Kang, ${ }^{2}$ Qifan Zhong, ${ }^{*}, 1$ Haitao Zhou, ${ }^{*}, 3$ Jianhong Yang, ${ }^{*}, 1,3$ De Chen, ${ }^{4}$ Yingtao Luo, ${ }^{2}$ Kaibin Chen, ${ }^{2}$ Wangxing Li ${ }^{1}$, Jin Xiao, ${ }^{1,5}$

1. School of Metallurgy and Environment, Central South University, Changsha, Hunan Province, China

2. Zhengzhou Non-ferrous Metals Research Institute Co. Ltd of CHALCO, Zhengzhou, Henan Province, China

3. School of Material Science and Engineering, Jiangsu University, Zhenjiang 212013, Jiangsu Province, China

4. Department of Chemical Engineering, Norwegian University of Science and Technology, 7491 Trondheim, Norway

5. National Engineering Laboratory for Efficient Utilization of Refractory Nonferrous Metals Resources, Central South University, Changsha, Hunan Province, China

E-mail address: 348259246@qq.com \&zhongqifanchina@csu.edu.cn 


\section{Details of the peel strength testing process}

Before testing, the ACNTs/Al foil composites were cut into ribbon foils with a width and length of $1.5 \mathrm{~cm}$ and $15 \mathrm{~cm}$, respectively. The $3 \mathrm{M}$ VHB tape (wideness $25 \mathrm{~mm}$ ) was placed on a PVC plate, following the carbon nanotube forest were attached on the $3 \mathrm{M}$ VHB tape. After that, a steel roller $(2 \mathrm{~kg})$ covered with rubber was used to roll the tape and the $\mathrm{Al}$ foil/carbon nanotube film above firmly for three times at the rate of $300 \mathrm{~mm} \cdot \mathrm{min}^{-1}$ to ensure a good contact between the ACNTs and 3M VHB tape. Consequently, the tape attached with carbon nanotube forest was placed on the PVC plate, then one end of the PVC plate was clamped to the testing machine tightly. During the testing, the Al foil/ACNTs film were moved away at the rate of 300 $\mathrm{mm} \cdot \mathrm{min}^{-1}$ by seizing the free end and back upon itself at an angle of $180^{\circ}$. The test schematic is shown as Figure S1. The contact area used for determining the peel strength was the geometrical area of the surface of the carbon nanotube forests covered with the tape. Therefore, the contact area was calculated by the wideness of carbon nanotube forest/Al foil film plus the length of the carbon nanotube forest/Al foil removed at least for 20 to $80 \mathrm{~mm}$ from the start point. The quantitative peel strength test was carried out for three times to ensure the accuracy of the testing results.

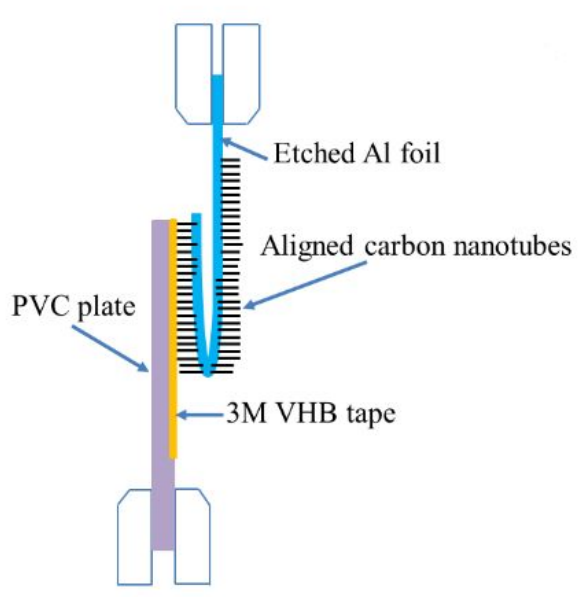

Figure S1 A schematic of peel strength test 


\section{The photographs of the ACNTs/etched Al foil in the bending test process}

Figure $\mathrm{S} 2$ is the photograph of the ACNTs/etched Al foil at flat state (A) and bending state (B). One bending cycle is counted from A to B, following from B to A. The samples chose for the electrochemical performance test are as the schematics of Figure 2C showed.

$\mathrm{ACNTs} /$ etched $\mathrm{Al}$ foil is flat $\mathrm{ACNTs} /$ etched $\mathrm{Al}$ foil is bent.

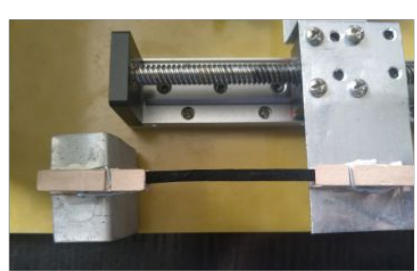

A

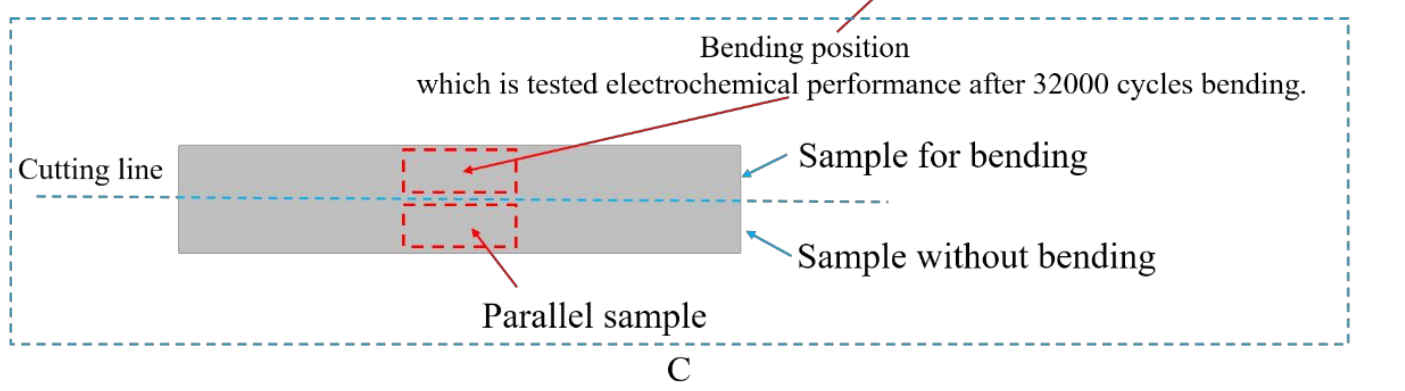

Figure S2 A photograph of the ACNTs/etched Al foil at flat state (A) and bending state (B), C-A schematic for choosing parallel samples with and without bending test to be used for electrochemical test 


\section{The electrochemical impedance spectroscopy analysis}

The commercial ZsimpWin software was used to fit impedance spectra in the whole frequency ranges. The equivalent circuits for fitting the impedance spectra of ACNTs/etched Al foil electrodes were presented as below.
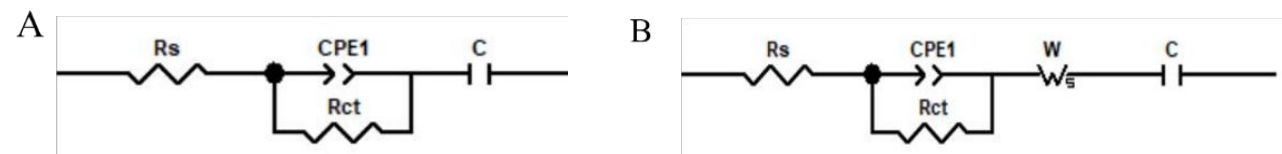

Figure S3 The equivalent circuits (A) for fitting the impedance spectrum of ACNTs/etched $\mathrm{Al}$ foil in $1 \mathrm{~mol} \cdot \mathrm{L}^{-1} \mathrm{TEABF}_{4} / \mathrm{AN}$ electrolyte, the equivalent circuit (B) for fitting the impedance spectrum of ACNTs/etched $\mathrm{Al}$ foil in $0.2 \mathrm{~mol} \cdot \mathrm{L}^{-1} \mathrm{Na}_{2} \mathrm{SO}_{4}$ solution

$\mathrm{R}_{\mathrm{s}}$ - The electrolyte resistance with some contribution of ohmic resistance of metal components and contact resistance between the ACNTs layer and substrate.

CPE1- Non-ideal constant phase element, representing the frequency dispersion which may be the result of surface heterogeneity.

$\mathrm{R}_{\mathrm{ct}}$ - The charge transfer resistance.

W- Warburg diffusion impedance which was attributed to the ion diffusion.

C-The electrical double-layer capacitor 


\section{The thermal dissipation performance testing of ACNTs grown on etched Al}

foil

The structure designed for the experiments was consisted of a thermometer chip mounted on a fixed position of the backboard of a 24W LED light. And silicone thermal conductive adhesive was used to make sure that the ACTNs/etched Al foil composite was mounted on the LED backboard tightly. Reference measurements were also done without anything being pasted on or only with etched $\mathrm{Al}$ foil being stuck on the backboard of LED respectively, but otherwise under the same conditions. The ambient temperature stabilized at $25^{\circ} \mathrm{C}$ during the testing process for all the experiments.

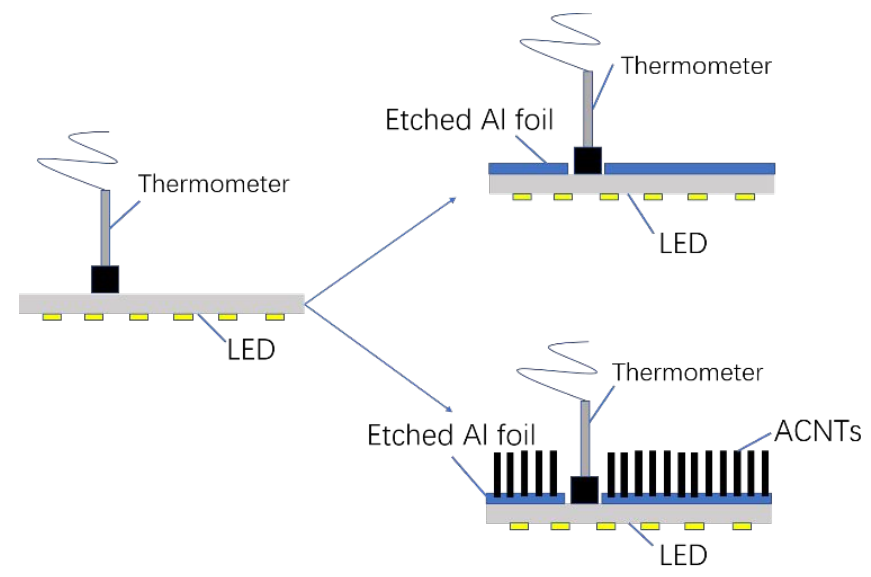

Figure S4 A schematic illustration of testing process of the temperature variation of LED light after being turned on, which was without and with the etched Al or ACNT/etched Al foil as thermal dissipation substrate being attached on. 
5. The location of the ordinary and etched Al foil in the horizontal CVD reacting quartz tube

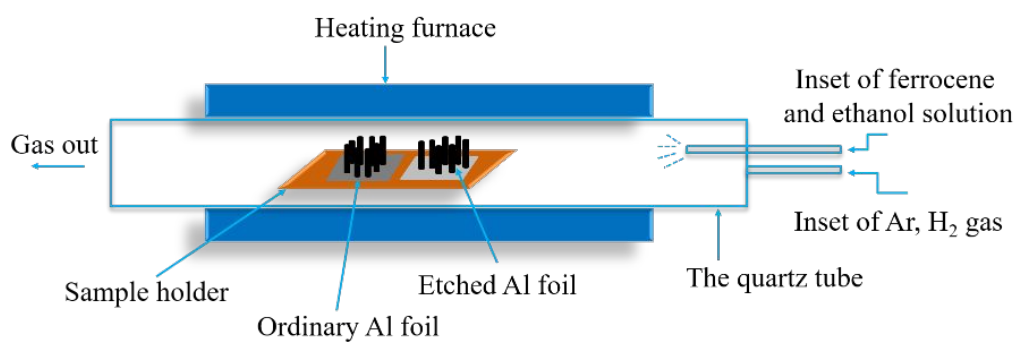

Figure S5 A schematic of CVD reactor and the location of the etched and ordinary Al foil in the quartz tube 


\section{Pictures of ACNTs/etched Al foil produced in the scale-up experiment}

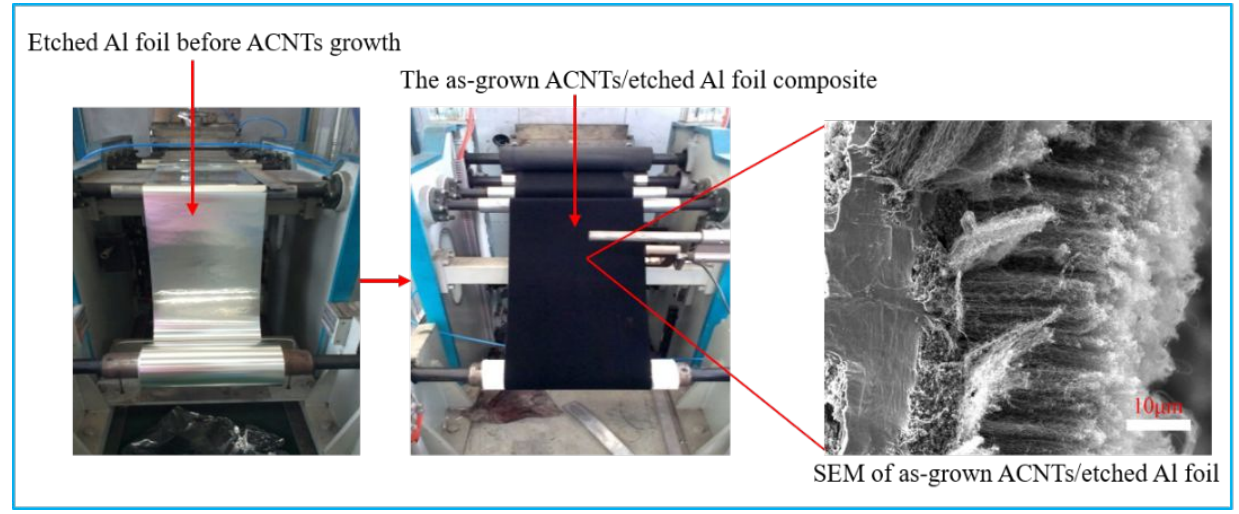

Figure S6 The ACNTs/etched Al foil pictures in pilot production and the SEM of as-grown ACNTs/etched Al foil 


\section{The electrochemical performances of PANI $\left(\mathrm{MnO}_{2}\right) / \mathrm{ACNT} / \mathrm{etched}$ Al foil composites}

Briefly, before the polyaniline (PANI) deposition, the ACNTs were pre-treated by plasma functionalization to improve the hydrophilicity. Subsequently, the PANI were synthesized by one-step method on a conventional three-electrode system. An aqueous electrolyte solution of $1 \mathrm{~mol} \cdot \mathrm{L}^{-1} \mathrm{H}_{2} \mathrm{SO}_{4}$ (Sinopharm) with $0.1 \mathrm{~mol} \cdot \mathrm{L}^{-1}$ aniline (Sigma-Aldrich) was used for the CV electrochemical deposition of PANI on the ACNTs/etched Al foil electrode. The synthesis of PANI was carried out at the potentials between $-0.2-0.8 \mathrm{~V}$ (vs. $\mathrm{Ag} / \mathrm{AgCl}$ reference electrode) at the scan rate of $10 \mathrm{mV} \cdot \mathrm{s}^{-1}$ for 19 scan cycles. ${ }^{1}$ Manganese dioxide $\left(\mathrm{MnO}_{2}\right)$ was prepared by immersing ACNTs/etched $\mathrm{Al}$ foil in $0.2 \mathrm{~mol} \cdot \mathrm{L}^{-1} \mathrm{KMnO}_{4}$ (Sinopharm) aqueous solution for $1.5 \mathrm{~h}$ at the temperature of $70{ }^{\circ} \mathrm{C},{ }^{2}$ after that, a thin layer of nanostructured $\mathrm{MnO}_{2}$ was deposited on the surface of ACNTs. The resulting PANI or $\mathrm{MnO}_{2} / \mathrm{ACNTs}$-etched $\mathrm{Al}$ foil was rinsed with deionized water and ethanol, and finally dried at $60{ }^{\circ} \mathrm{C}$ in vacuum oven for $24 \mathrm{~h}$.

The electrochemical performance testing of PANI/ACNTs-etched Al foil was studied in a three-electrode system in $1 \mathrm{~mol} \cdot \mathrm{L}^{-1} \mathrm{H}_{2} \mathrm{SO}_{4}$ solution. A silver/silver ion electrode $(\mathrm{Ag} / \mathrm{AgCl})$ was used as the reference electrode and a Pt mesh was used as the counter electrode. The specific capacitance $\left(\mathrm{C}_{\mathrm{sp}}\right)$ of PANI/ACNTs was calculated at the potentials between -0.2-0.7 V (vs. $\mathrm{Ag} / \mathrm{AgCl}$ reference electrode). The electrochemical performance measurements of $\mathrm{MnO}_{2} / \mathrm{ACNTs}$-etched $\mathrm{Al}$ foil and ACNTs/etched $\mathrm{Al}$ foil were also carried out in $0.2 \mathrm{~mol} \cdot \mathrm{L}^{-1} \mathrm{Na}_{2} \mathrm{SO}_{4}$ solution and the cyclic voltammetry electrochemical potential window was between -0.2 and $0.7 \mathrm{~V}$ (vs. $\mathrm{Ag} / \mathrm{AgCl}$ reference electrode). Both the $\mathrm{CV}$ responses of the PANI and $\mathrm{MnO}_{2}$ electrodes were measured at scan rate of $5 \mathrm{mV} \cdot \mathrm{s}^{-1}$. The specific capacitance $\left(C_{s p}\right)$ for PANI/ACNTs, $\mathrm{MnO}_{2} / \mathrm{ACNTs}$ was evaluated from the $\mathrm{CV}$ curves, according to the equation (1) as 
below:

$$
C_{s p}=\frac{I}{2 M(d V / d t)}
$$

Where $I$ is the sweeping current, and $d V / d t$ is the scanning rate of voltage, $M$ is the effective mass of PANI, $\mathrm{MnO}_{2}$ electrode, respectively, $C_{s p}$ is the specific capacitance obtained by equation (1).

The galvanostatic charge/discharge (GCD) curves of PANI/ACNTs-etched Al foil and $\mathrm{MnO}_{2} / \mathrm{ACNTs}$-etched $\mathrm{Al}$ foil were measured at the current densities of $2.5 \mathrm{~A} \cdot \mathrm{g}^{-1}$ relative to the mass of PANI/ACNTs or $\mathrm{MnO}_{2} / \mathrm{ACNTs}$, while the potential voltage were both between -0.2-0.7 V vs. $\mathrm{Ag} / \mathrm{AgCl}$ reference electrode. The electrochemical impedance spectroscopy (EIS) measurements were carried out from $100 \mathrm{kHz}$ to 0.01 $\mathrm{Hz}$ while applying an $\mathrm{AC}$ potential of $5 \mathrm{mV}$.
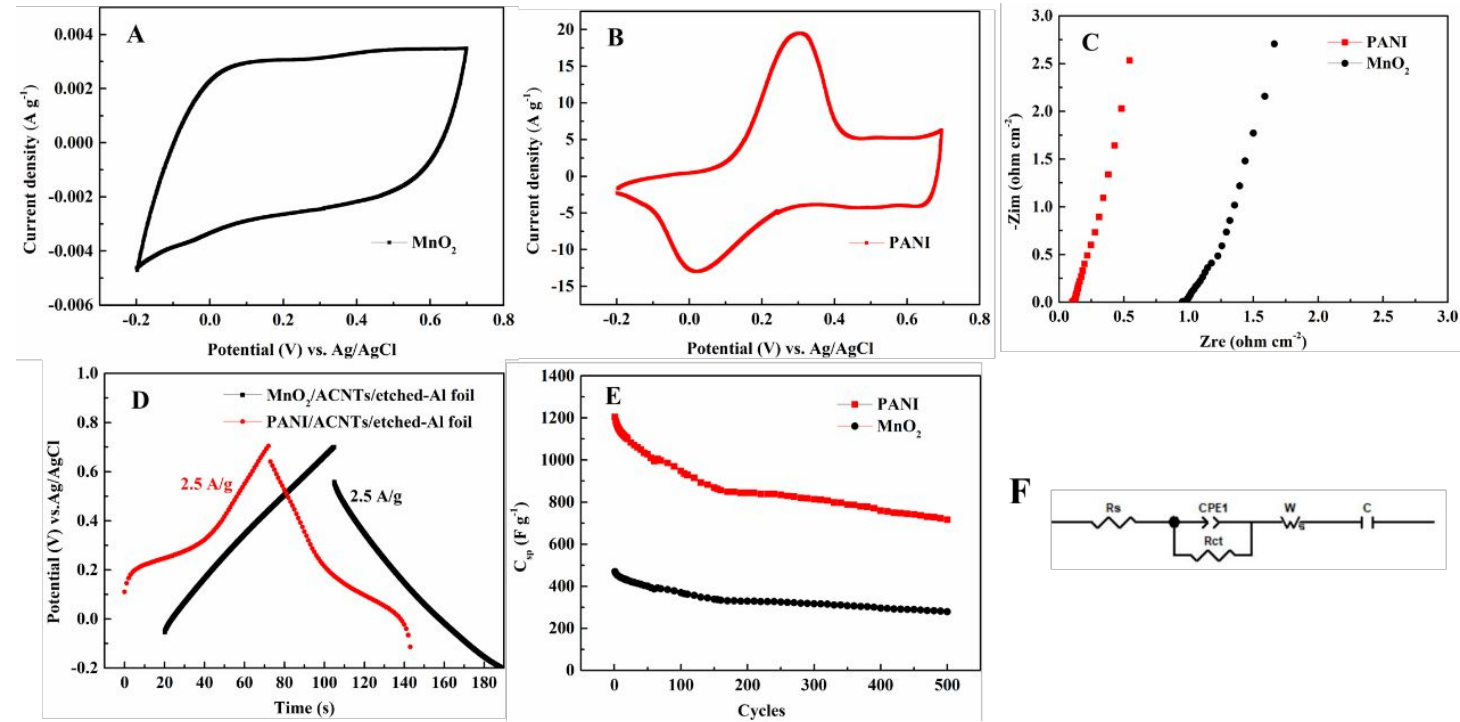

Figure S7 A-CV curve of the $\mathrm{MnO}_{2} / \mathrm{ACNTs}$-etched $\mathrm{Al}$ foil $\left(0.2 \mathrm{~mol} \cdot \mathrm{L}^{-1} \mathrm{Na}_{2} \mathrm{SO}_{4}\right)$. B$\mathrm{CV}$ curve of the PANI/ACNTs-etched Al foil $\left(1 \mathrm{~mol} \cdot \mathrm{L}^{-1} \mathrm{H}_{2} \mathrm{SO}_{4}\right)$. C-The Nyquist plot of EIS testing of $\mathrm{MnO}_{2} / \mathrm{ACNT}$ /etched $\mathrm{Al}$ foil and PANI/ACNTs/etched Al foil, respectively. D-The galvanostatic charge-discharge curves for $\mathrm{MnO}_{2} / \mathrm{ACNTs}$ (In 0.2 $\mathrm{mol} \cdot \mathrm{L}^{-1} \quad \mathrm{Na}_{2} \mathrm{SO}_{4}$ ) and PANI/ACNTs (In $1 \mathrm{~mol} \cdot \mathrm{L}^{-1} \quad \mathrm{H}_{2} \mathrm{SO}_{4}$ ), respectively. E-The cycling performances for $\mathrm{MnO}_{2} / \mathrm{ACNT}$ sand PANI/ACNTs solution, respectively. F- 
The equivalent circuit for fitting the impedance spectra of PANI (or $\mathrm{MnO}_{2}$ )/ACNTs-etched $\mathrm{Al}$ foil electrodes.

The ACNTs before coating usually showed very small current response in the CV curve. In contrast, after depositing PANI or $\mathrm{MnO}_{2}$ on the ACNTs, a great increasing in the capacitance were shown in the CV curves. The much larger current density of PANI/ACNTs or $\mathrm{MnO}_{2} / \mathrm{ACNT}$ s composites than the ACNTs alone was attributed to the redox reaction of PANI or $\mathrm{MnO}_{2}$. The $C_{s p}$ of PANI coating together with the ACNTs reached $1205.8 \mathrm{~F} \cdot \mathrm{g}^{-1}$ for the sample with the PANI mass loading of $\sim 40.51 \%$, and the $C_{s p}$ of $\mathrm{MnO}_{2}$ coating together with the ACNTs was $469.8 \mathrm{~F} \cdot \mathrm{g}^{-1}$ which the mass loading of $\mathrm{MnO}_{2}$ was about $34.9 \%$.

As shown in Figure S6-C, either the Nyquist plots of PANI/ACNTs or $\mathrm{MnO}_{2} / \mathrm{ACNTs}$ contained a distorted semicircle at high frequency due to the porosity of the electrodes and a linear part at low frequency was associated to a diffusion-controlled pseudo-capacitance resulting from Warburg behavior. The equivalent circuit for the electrodes was presented in Figure S6F. It was consisted of the elements of the internal resistance of the electrode $\left(R_{s}\right)$, double-layer capacitance $\left(C_{d l}\right)$ which was exist in parallel to the charge transfer resistance $\left(R_{c t}\right)$. The $C_{d l}$ was described by non-ideal constant phase element (CPE1), representing the frequency dispersion which may be the result of surface heterogeneity. Warburg diffusion impedance $Z_{w}$ was attributed to the ions diffusion and the elements $C$ represented the faradaic process of PANI or $\mathrm{MnO}_{2}$ redox transition. ${ }^{2,3}$ The fitting results of $R_{s}, R_{c t}$ were 0.106 $\Omega \cdot \mathrm{cm}^{-2}$ and $0.270 \Omega \cdot \mathrm{cm}^{-2}$ for PANI/ACNTs, respectively. And for $\mathrm{MnO}_{2} / \mathrm{ACNTs}$, the $R_{s}, R_{c t}$ were $1.055 \Omega \cdot \mathrm{cm}^{-2}$ and $0.04 \Omega \cdot \mathrm{cm}^{-2}$, respectively. The relatively low $R_{s}$ values of $\mathrm{MnO}_{2} / \mathrm{ACNT}$ and PANI/ACNTs were attributed to the short conductive path and reduced contact resistance provided by ACNTs grown on the current collector Al foil directly. The low $R_{s}$ and $R_{c t}$ were beneficial for improving charge-discharge rate of the composite electrodes. 
The galvanostatic charge-discharge (GCD) curves of PANI or $\mathrm{MnO}_{2} /$ ACNTs-etched Al foil at $2.5 \mathrm{~A} \cdot \mathrm{g}^{-1}$ were showed in Figure S6-D. The quasi-symmetrical GCD curves for $\mathrm{MnO}_{2} / \mathrm{ACNT}$ and the GCD curves for PANI/ACNTs deviated from the linear symmetrical shapes were corresponding to the behavior of cyclic voltammetry (Figure S6-A, B) respectively. The cycling performances of the PANI (or $\mathrm{MnO}_{2}$ ) /ACNTs-etched Al foil was also studied at a current density of $2.5 \mathrm{~A} \cdot \mathrm{g}^{-1}$ in $1 \mathrm{~mol} \cdot \mathrm{L}^{-1}$ $\mathrm{H}_{2} \mathrm{SO}_{4}$ and $0.2 \mathrm{~mol} \cdot \mathrm{L}^{-1} \mathrm{Na}_{2} \mathrm{SO}_{4}$, respectively. As shown by circular data points in Figure S6-E, the gravimetric capacitance of PANI/ACNTs in the first cycle was 956 $\mathrm{F} \cdot \mathrm{g}^{-1}$, which decreased to $814.5 \mathrm{~F} \cdot \mathrm{g}^{-1}$ in the 500 th cycle corresponding to $85.2 \%$ maintenance compared to initial capacitance. For $\mathrm{MnO}_{2} / \mathrm{ACNT}$ composite, the initial $C_{s p}$ was about $391.5 \mathrm{~F} \cdot \mathrm{g}^{-1}$. It decreased to $231.4 \mathrm{~F} \cdot \mathrm{g}^{-1}$ exhibiting the $C_{s p}$ retention of $59.1 \%$. Nevertheless, further improvement of the electrochemical performances of PANI $\left(\mathrm{MnO}_{2}\right) / \mathrm{ACNT}$-etched $\mathrm{Al}$ foil electrodes would be carried out by varying the PANI $\left(\mathrm{MnO}_{2}\right)$ loading while maintaining a thin coating film of PANI $\left(\mathrm{MnO}_{2}\right)$ on the surface of each ACNTs to make the most effective usage of the active materials for electrochemical energy storage possible. ${ }^{4}$

Generally speaking, the ACNTs/etched Al foil with much lower interfacial resistance was a relatively suitable binder free current collector for the synthesis of PANI $\left(\mathrm{MnO}_{2}\right) /$ ACNTs composites. Moreover, the 3D microscopically open structure of ACNTs could not only enhance the mechanical property of PANI or increase the electrical conduction of $\mathrm{MnO}_{2}$, but also optimized the electrolyte ion diffusion path for the redox reaction of the composite electrodes. The 3D micro-structure, flexible and bind-free ACNTs/etched Al foil composite material were benefit to take full advantages of the PANI, $\mathrm{MnO}_{2}, \mathrm{ACNT}$-etched $\mathrm{Al}$ foil to being used as electrochemical electrodes. 


\section{REFERENCES}

(1) Lou, F.; Chen, D. Aligned Carbon Nanostructures Based 3D Electrodes for Energy Storage. J. Energy Chem. 2015, 24 (5), 559-586.

(2) Mondal, S. K.; Prasad, K. R.; Munichandraiah, N. Analysis of Electrochemical Impedance of Polyaniline Films Prepared by Galvanostatic, Potentiostatic and Potentiodynamic Methods. Synth. Met. 2005, 148 (3), 275-286.

(3) Chen, W.; Rakhi, R. B.; Alshareef, H. N. Facile Synthesis of Polyaniline Nanotubes Using Reactive Oxide Templates for High Energy Density Pseudocapacitors. J. Mater. Chem. A 2013, 1 (10), 3315-3324.

(4) Huang, F.; Chen, D. Towards the Upper Bound of Electrochemical Performance of ACNT@polyaniline Arrays as Supercapacitors. Energy Environ. Sci. 2012, 5 (2), 5833-5841. 